\title{
Emotional Maps: Participatory Crowdsourcing of Citizens' Perceptions of Their Urban Environment
}

Public participation and civic engagement in the urban planning process are societal trends that stretch across countries, cultures, and classes. After decades of communist regimes in the Eastern Bloc, where there was basically no civic participation, civic society in the Czech Republic began to engage in discussions with the authorities, and citizens became more active in local planning. In 1994 eleven municipalities started the Network of Healthy Cities of the Czech Republic as a platform for sharing good practices in sustainable development and local participation. In the last three years, members of the Network have used emotional mapping activities to facilitate and improve the process of participatory planning. This paper describes the timeline of development and the deployment of an emotional mapping methodology in various workshops in the Healthy Cities network. A total of forty-six emotional mapping workshops were organised in thirty-five municipalities of the Czech Republic. The paper presents the change from crayon-based maps to digital web-mapping platforms; and presents a case study of the Prague 12 district, where emotional mapping workshops were used to explore the perception of safety, among other issues.

KEYWORDS: emotional mapping; methodology; neocartography; public participation; Prague 12

\section{INTRODUCTION}

INTERNATIONALLY, DEMOCRATIC MOVEMENTS that encouraged and supported participatory activism involved community members in local planning and development decision-making as early as the 1930s (Guldi 2017), and in the 1940s Demerath (1947) suggested that social scientists could help city planners to increase community participation in the planning process. The United States Economic Opportunity Act of 1964 urged "maximum feasible participation" in state-funded urban and rural community programmes (Economic Opportunity Act of 1964), and in 1965, the Planning Advisory Group in the United Kingdom presented a directive calling for public participation in plans issued under the Town and Country Planning Act (Taylor 1998). However, probably one of the most influential statements from that era was an essay by Sherry Arnstein (1969), "A Ladder of Citizen
Participation," in which the Californian social worker argued that "participation without redistribution of power is just an empty and frustrating process for the powerless" (216). Similarly, students protesting in Paris in $1968^{1}$ understood that participation does not guarantee change (Figure 1) if it is not supported and implemented by those in power (Arnstein 1969). By the 1970s and 1980s participatory mapping projects were used by poor and indigenous peoples in Asia, Africa, and North and South America to advocate for their right to water, land, and culture (Chambers 1994a; Tulloch 2007; Pánek 2016).

All of these processes took place outside the former Eastern Bloc, so the Czech Republic does not share a history of public participation in urban planning and decision-making processes. It was only after the Velvet Revolution in

1. 1968 was the same year as the Prague Spring and the Warsaw Pact invasion of Czechoslovakia. 
1989, when civil society in the former Czechoslovakia reemerged, that citizens became more active in shaping the shared places in which they lived.

The Network of Healthy Cities of the Czech Republic (HCCZ) was created in 1994, and its mission is to encourage $\mathrm{Czech}$ municipalities to stipulate in their statutes that they will consistently work towards sustainable development, health, and quality of life in cities and regions of the Czech Republic. Among the first steps in increasing citizens' quality of life were the publication of the booklet Methodology of Sustainable Development and the holding of annual Forum of the Healthy City events. Both of these were implemented in order to engage citizens in local planning, but it was only with the rise of the Internet and crowdsourcing that the "democratisation of cartography” (Rød, Ormeling, and van Elzakker 2001) could start. OpenStreetMap in 2004, followed by Google Maps in 2005, opened the vast world of mapping to the general population, and it was no longer necessary to have a formal education related to cartography or planning to add points/lines/polygons to a world map. Participatory planning support systems such as FixMyStreet, CitySourced, and Maptionnaire opened new opportunities for citizens to become involved in planning processes.

In $2014 \mathrm{HCCZ}$ implemented emotional mapping workshops in their Forum of the Healtby City workshop, which is the first contact and also the annual meeting between the local administration and citizens. I coordinated the emotional mapping workshops at $\mathrm{HCCZ}$; this paper combines my personal experience with a descriptive analysis of the process involved in developing a methodology for the collection and visualisation of citizens' perceptions of how they experience the city. This paper describes (1) past experiences with different modes of collecting the emotional data during the workshops, (2) the various methods tested for the visualisation of the results, and (3) the current version of my web app for the participatory crowdsourcing

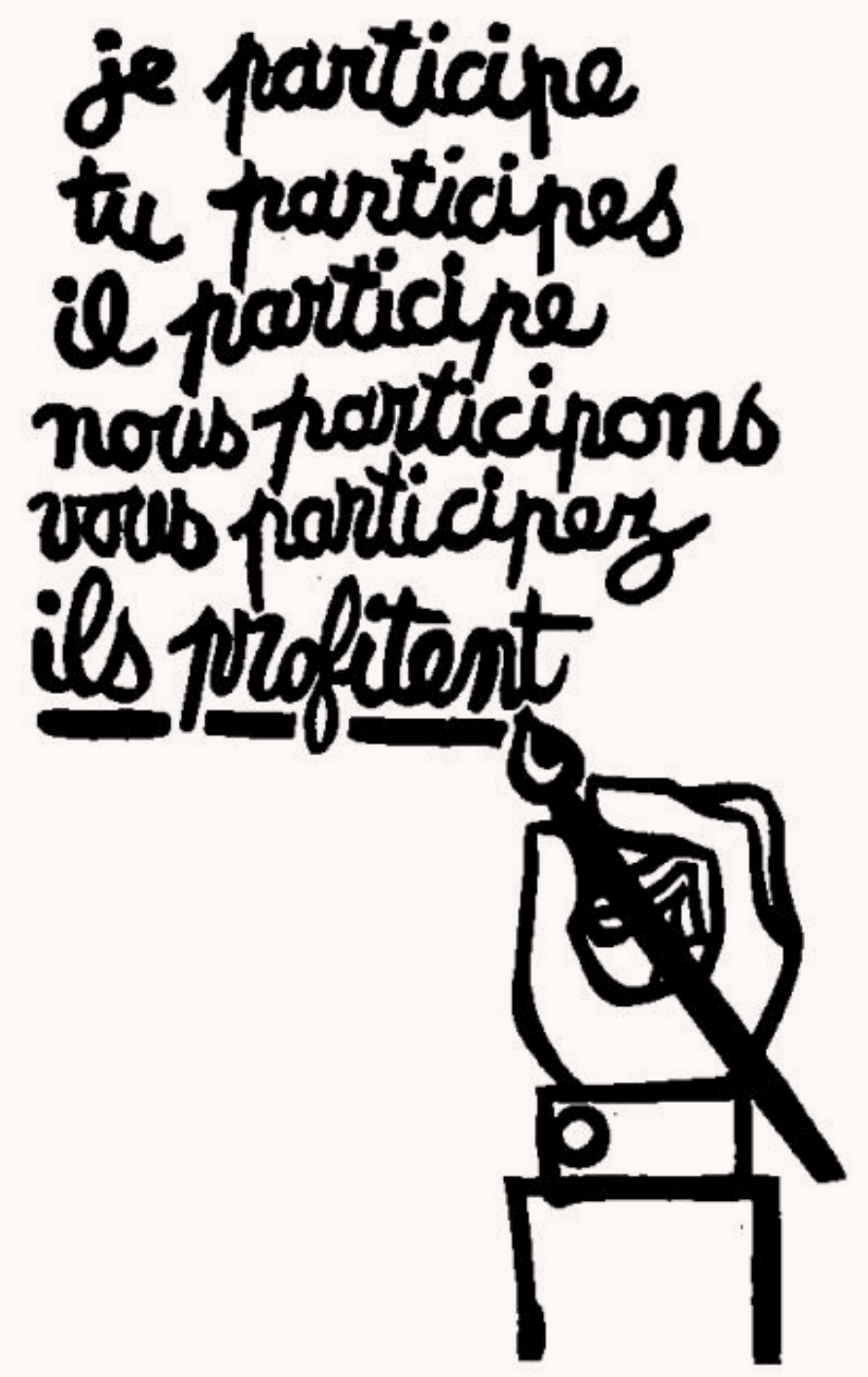

Figure 1. French student poster from 1968 created at Atélier Populaire. In English it reads, "I participate / you participate / he participates / we participate / you participate / they profit."

of citizens' perceptions of their urban environment. As the over-reporting of successes is considered to be one of the plagues of community development (Botes and van Rensburg 2000), I will also focus on failures in my research and methodologies in order to broaden the current state-of-the-art in the area of emotional mapping.

\section{WHAT ARE EMOTIONAL MAPS?}

Emotional mapping, As Understood in the field of participatory planning, is a method that allows citizens and municipalities to initiate a map-based dialogue concerning the current and future state of public space, drawing upon their experiences of that place. The method can be considered to be a subgroup of Public Participation GIS (PPGIS) methods (Brown and Kyttä 2014) and at the same time as a tool of GeoParticipation (Pánek 2016). GeoParticipation, which is the use of spatial tools in order to involve citizens in community participation, further 
develops PPGIS as it provides an easy-to-use environment for social engagement while creating a feeling of belonging to a certain social group or community (Pánek 2016).

One of the first examples of emotional mapping in urban visualisation comes from a book of essays entitled Emotional Cartography: Technologies of the Self (Nold 2009). The book was described by Nold as "a collection of essays by artists, designers, psychogeographers, cultural researchers, futurologists and neuroscientists, brought together by Christian Nold to explore the political, social and cultural implications of using technology to visualise intimate biometric data and emotional experiences" (3). Surprisingly, the publication has no essays by cartographers or city planners, although emotions have a strong influence on how the (urban) environment is perceived and on how people perceive a spatial layout (Zadra and Clore 2011). Emotions are the crucial part of every human being and yet their presence on maps and in spatial data is rare (Griffin and McQuoid 2012).

Emotional mapping has the tools to support the ideas of Mody, Willis, and Kerstein (2009), who believe that emotions, spaces, and places are interconnected and that every location can evoke an emotion. As Korpela (2002, 363373) says, places can be seen as attractive, boring, dangerous, or scary, among other perceptions. Not only can basic emotions - as defined by Ekman (1992) — be mapped, but also more specific perceptions and ideas about the utilisation of public space can be placed on the map. It's possible to argue that emotional mapping is not the correct term, because emotions are not the only things that are mapped; the maps also include people's perceptions of and experiences in a place. Questions related to the lack of parking spaces and issues such as where to place a new statue can be examples of non-emotional spatial questions.

Creating a map within a community has an empowering effect because members of the community have the opportunity to think spatially about their environment and literally put their community, their perceptions, and their emotions on the map. The process of creating the data triggers feelings of belonging to the community and ownership of the future. With ownership comes the onset of empowerment, leading to sustainable development, driven and run by the community itself (Vlok and Pánek 2012). This has been observed in various communities and it is also the reason that incorporating emotions in community planning has its proponents (Bergner et al. 2011; Raslan, Al-Hagla, and Bakr 2014; Curtis 2012).

Participation has become an integral part of geographical research since behavioural geographers started working with place perception and Kevin Lynch (1960), along with Peter Gould and Rodney White (1974), used the concept of mental maps to explore urban visualisation and spatial preferences. Later, when Robert Chambers (1994a; 1994b; 1994c) and others introduced maps into Participatory Rural Appraisal, Participatory GIS and PPGIS were also recognised by quantitative geographers as research methods and visualisation tools. With the rise of participatory approaches to GIS, sketch maps have appeared as an alternative form of data collection to mental maps. Unlike mental maps, which are often free-form drawings from memory, sketch maps are more likely to be georeferenced and to represent the actual experiences of the participants (Boschmann and Cubbon 2014).

Emotional mapping combines the mental mapping heritage of behavioural geography with sketch maps' integration of GIS in order to visualise, overlay, and analyse results that are voluminous in the number of respondents as well as in the representations collected. These emotional maps, in contrast to mental maps, are a spatially accurate mode of data collection and use a base map as a background for respondents' drawings. Unlike sketch maps, which are often used as an additional data source in surveys and interviews (D'Antona, Cak, and VanWey 2008), emotional maps are usually the sole data source used in the research.

Emotional maps, as implemented in the research described here, work with people's perceptions of their spatial environment and are used to understand and explain participants' decision-making and behaviour in an urban space (Kitchin, Blades, and Golledge 1997; Spencer and Dixon 1983). In the HCCZ workshops, the primary source of the experiences presented in this paper, users are often asked to identify places on the map where they feel afraid (mapping of safety), where they "like it" (positive emotional responses), where they spend their free time (planning leisure-time activities), and where it is "dirty" (environmental pollution, etc.). The answers to this variety of spatial perception questions can hardly be considered to be the totality of emotional responses to the place, but could fit under the umbrella term emotional mapping. 
Some authors use terms such as sentiment mapping (Caragea et al. 2014; Kocich 2018), hedonic mapping (Ennis and Ennis 2013), ephemeral mapping (Art \& Cartography Commission of ICA 2014), perceptual mapping (Doran and Burgess 2011), or sketch mapping (Boschmann and Cubbon 2014), among many others to describe people's experience of places. The theoretical discussions and uncertainty about the terminology show that emotional mapping research and practice is neither clearly defined nor anchored in its respective disciplines. Nevertheless, I will use the term emotional mapping, mainly based on the argument of Perkins (2009, 130), who states that "emotional maps which chart human feelings onto a cartographical landscape . . . and allow users to devise and customise their own emotional landscape, to choose what kinds of thoughts and experiences, feelings and passions, to map"; but also as nod to the a legacy of Nold's Emotional Cartography (2009).

\section{METHODOLOGY DEVELOPMENT}

During the process of testing, developing, and deploying the emotional mapping workshops, I tried various mapping techniques and achieved diverse results. The first map was created using six large crayons and one A1-sized map (Figure 2) of the city Třebič at a meeting of the municipality with the citizens. A total of 65 people participated in the workshop. The idea of using crayons came from the influential book by Robert Chambers Whose Reality Counts? Putting the First Last (2003), in which Chambers argues that (community) development experts should "hand over the stick" to let people draw their own maps. While it may be easy for a facilitator to hand over the stick to the participants, it is not so easy to share the crayon among the participants. There is always somebody who wants to take control of the tool and effectively take control of the map. As there were usually only two pieces of the same colour crayons, participation was not equal and some citizens may have felt excluded. The second disadvantage of this method was that, if three or more colours were overlaid, it was impossible to identify the original colours as they all became shades of grey.

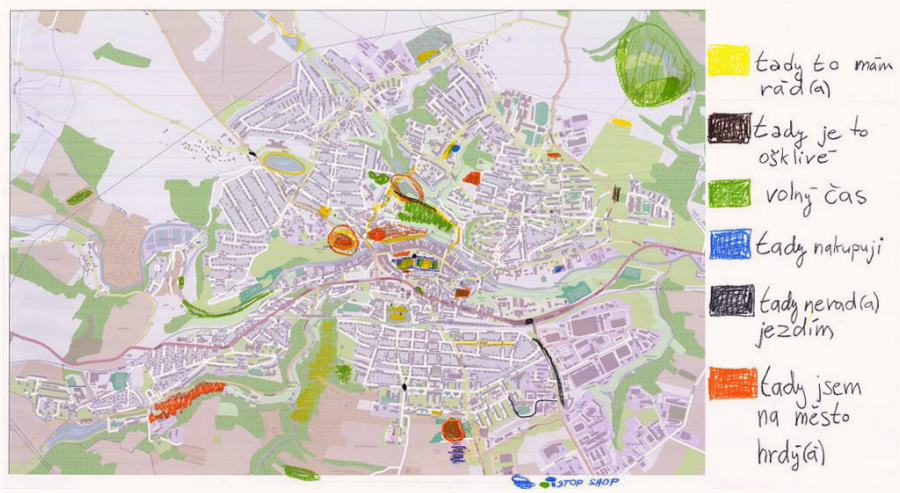

Figure 2. Example of the analogue emotional map created at the first emotional mapping workshop in 2014.
With the first attempt of emotional mapping (Figure 2) being unsuccessful and useless, it was necessary to develop a method where all citizens had an equal opportunity to participate in the creation of the map and to ensure that the visual outcome was also readable. Using crayons may have been creative and useful while working with children, but as a serious tool for participatory mapping it lacks accuracy and is difficult to digitize.

The second version of analogue emotional mapping involved coloured pins (Figure 3), which the participants pinned onto a map on a corkboard. This solved the overlay issue (as opposed to using coloured stickers that overlay

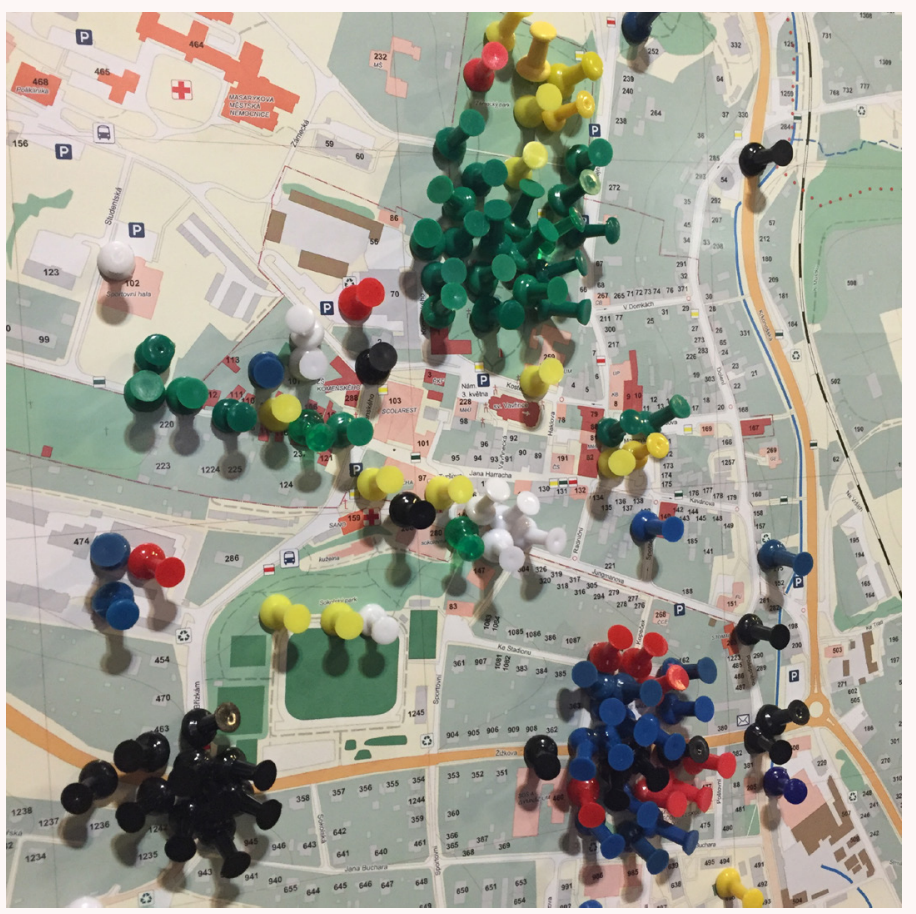

Figure 3. Example of using colourful pins for creating an emotional map in 2016. 


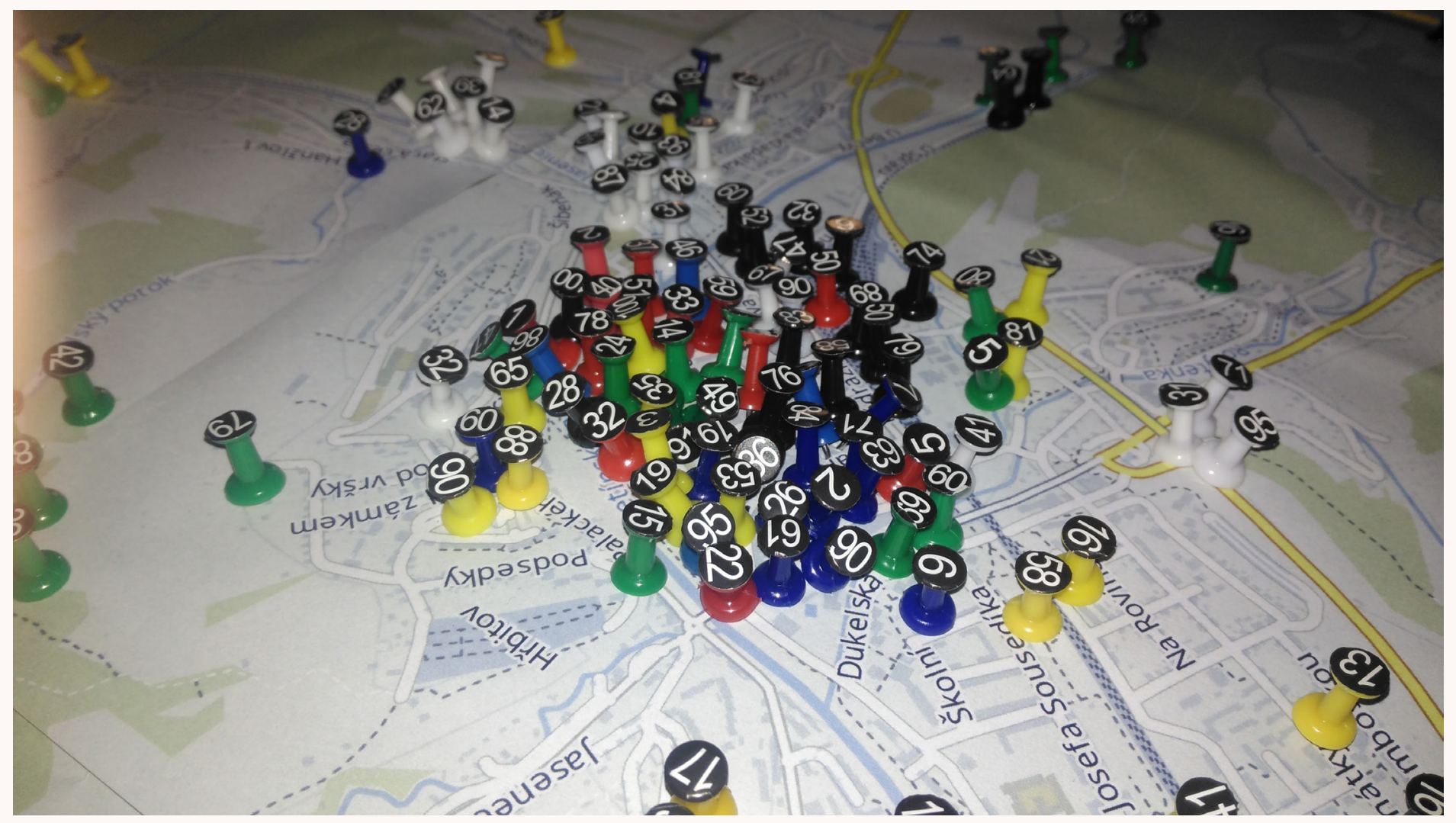

Figure 4. Colourful pins with numbers used to identify the authors and link them with respective complaints.

each other) as well as the hand over the stick problem, as there were always more than one hundred pins of each colour. Participants could use as many pins as they wished, and several pins in the same location created easily visible hotspots and also produced a 3D effect on the map. When pins are used, each colour represents a different emotion, and when the results are digitised, each pin is represented as a single point, as opposed to the first mapping attempt, which required combinations of points, lines, and polygons. The change from multiple geometries towards points only was due to difficulties in combining multi-feature datasets in GIS and the experience of other authors' research: up to now the predominant methods for spatially-explicit preference mapping have been marking points for locations or sketching polygons annotated with expressions of preference (Jankowski et al. 2016). Furthermore, Brown and Pullar (2012) suggested that points instead of polygons be used in future PPGIS applications, although their study was focused on mapping large-scale landscape values. Huck, Whyatt, and Coulton (2014) suggested using a fuzzy, multi-point feature called a Spraycan to collect the information, but I decided to only use single points as, in my experience, I have found that points are often more specific and place-related than polygons or multipoint features. Also it would be technically very complicated to recreate fuzzy collections of multiple points with pins in the analogue version of the workshop. Nevertheless, with specific topics (bike lanes, air pollution, perceptions of city centre boundaries), different feature types may prove to be more convenient.

A further improvement in the emotional mapping workshops organised by the HCCZ was made by linking each pin with its author's demographic profile via numbers on the pins (Figure 4). Comments were also written with the same number code on the side. Thanks to this approach, the data gathered later via an online tool and the data from participatory mapping meetings were almost totally comparable and hence could be integrated into one large dataset. The ability to combine the datasets also allowed me to combine various target groups, as some respondents tended to prefer face-to-face meetings and communal gatherings, while others preferred the anonymous online form of participation. Information from the demographic profiles 


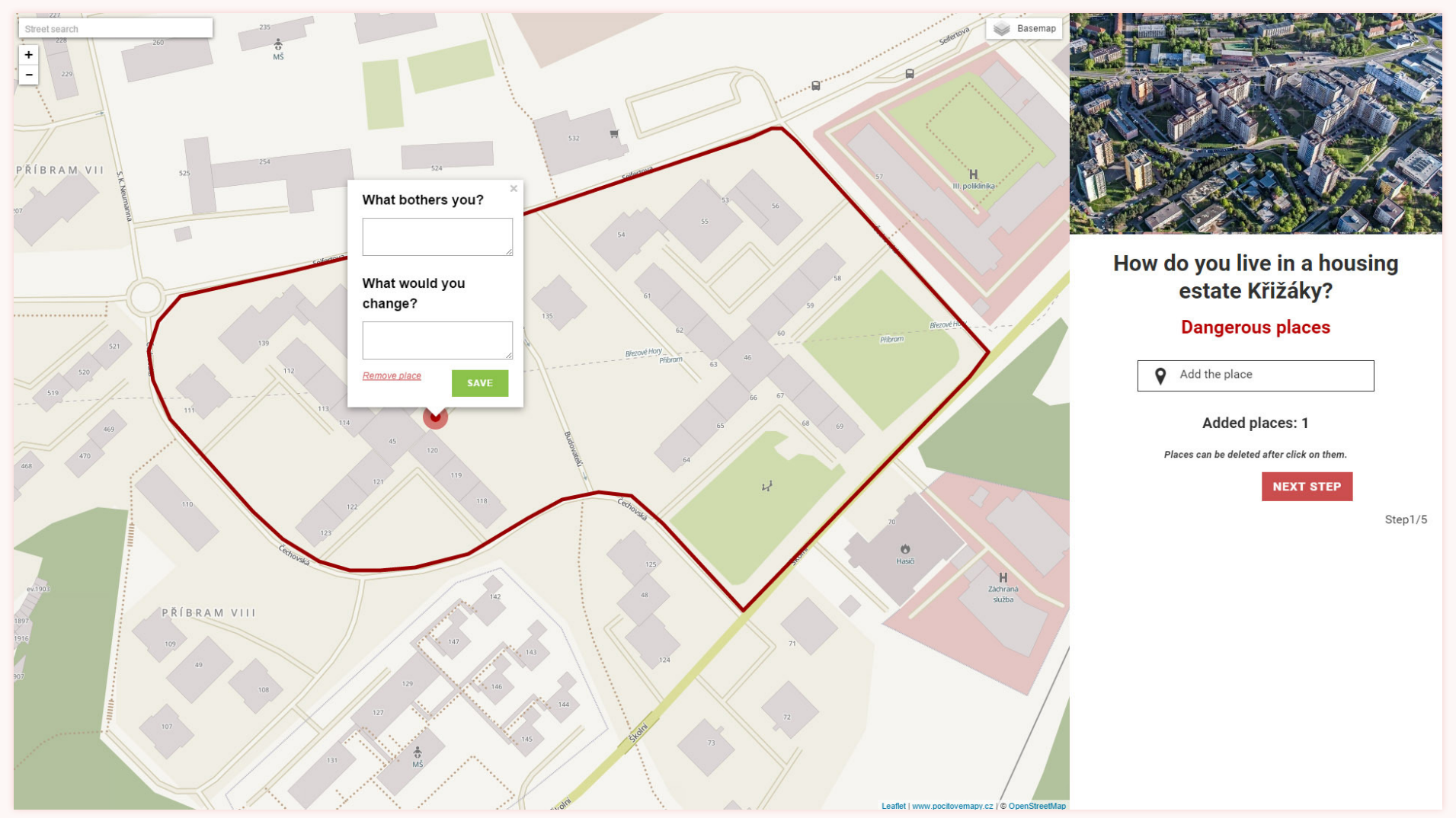

Figure 5. The web application created for participatory consultation on a neighbourhood revitalisation plan in Príbram, the Czech Republic, in 2015.

was later used to better filter the results and to create a series of maps of the same topic based on the respondents' profiles (gender, age, income, etc.).

Besides organizing participatory emotional mapping workshops, I also co-created PocitoveMapy.cz (Figure 5), a single-page web application that uses two open-source JavaScript libraries: jQuery for basic user interactions and app control, and Leaflet for map interactions. The results from the front end are sent asynchronously to the back end, which uses a simple Model-View-Controller framework written in the PHP scripting language. A MySQL database is used for storing metadata from users, and geodata are stored in GeoJSON format. The collection of emotional mapping data is also made possible with the help of a CSS framework and Bootstrap, and administrators are allowed to download the full metadata from MySQL, concatenated with GeoJSONs.

The gradual development of the analogue methodology was complemented by increasing the functionality of the web interface used for both collecting and visualising the data. As mentioned previously, combining feature types is undesirable and this was proved not only by the inability of GIS to perform advanced analyses on multiple feature types stored in one file, but also during attempts at visualisation (see Figure 6), when large polygons often covered the whole study area and thus decreased the utility of collected data and made it more difficult to analyse such datasets. Although the multiple feature types could be converted to raster as tested by Šerý and Šimáček (2012), the overwhelming area of large polygons still dominated

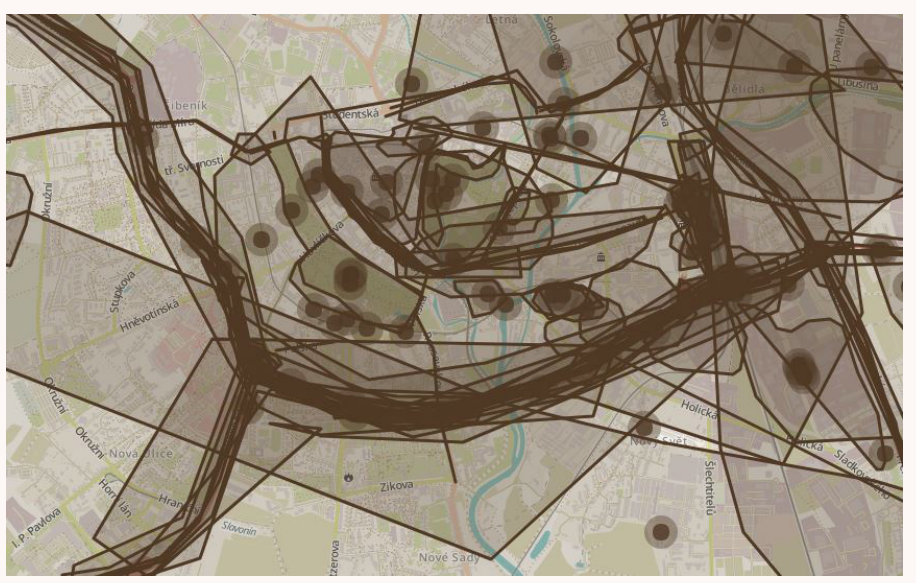

Figure 6. A failed attempt at using three feature types (points, lines, and polygons) to collect data about air pollution in Olomouc, Czech Republic. 

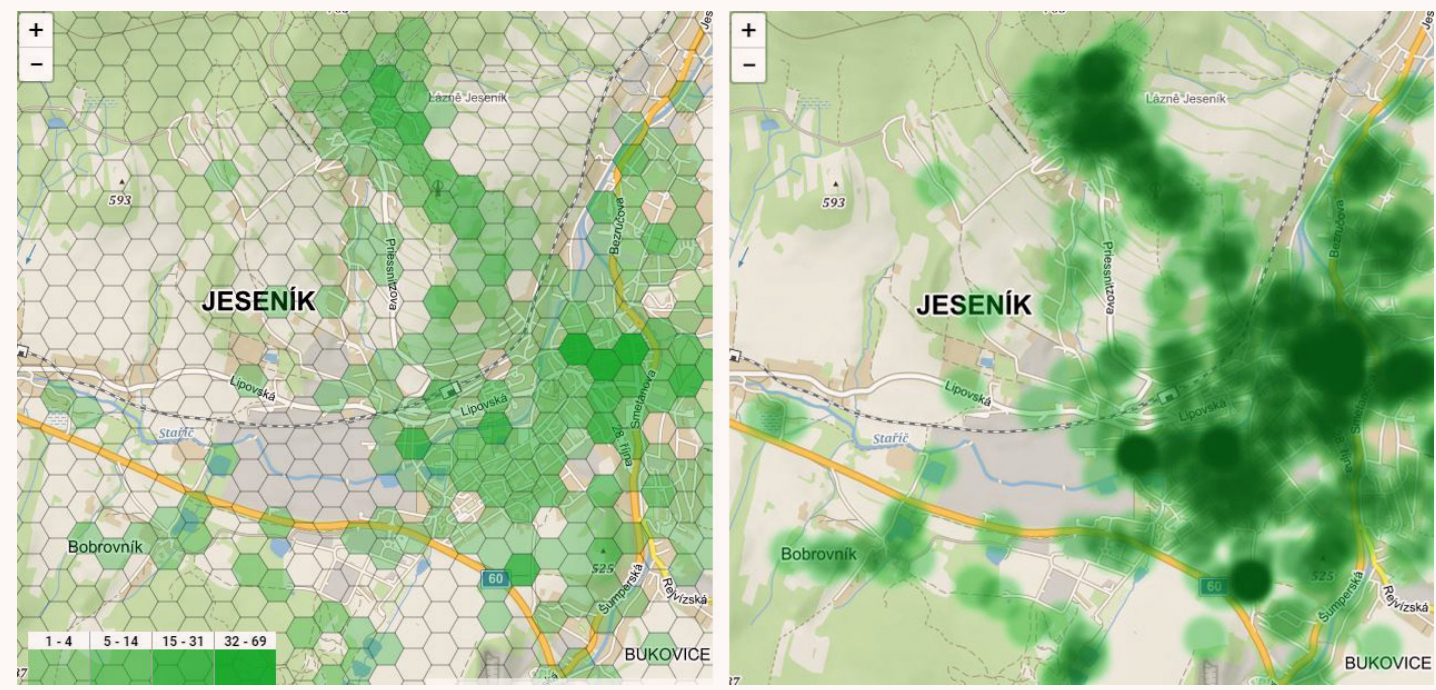

Figure 7. Left: hexagons (side $=200 \mathrm{~m}$ ) used to visualise the collected data. Right: a heatmap visualisation of the same data.

and affected the final results. Therefore, the application's original functionality, which allowed respondents to choose from points, lines, and polygons (clicking or handdrawn) was usually limited to one feature type only. With the growing ability of Czech municipalities to attract people to participatory mapping activities, local political representatives realised that it was not only necessary to ask spatial questions, but that it might also be possible, via the web app, to create questionnaires with complex questions and embedded maps. Therefore, functionality to create non-spatial questions was added in 2016.

As the platform is also used to visualise the results, the original points only visualisation was soon complemented with two other visualisation methods: (1) a hexagonal grid (Figure 7, left) formed from the aggregation of points, and (2) a heat map (Figure 7, right) visualisation.

Hexagons are used as they were identified as the optimal shape for delimiting urban areas in previous research (Burian, Pászto, and Langrová 2014). They are also used in ecological modelling (Birch, Oom, and Beecham 2007) as well as in self-organising maps (Jiang and Harrie 2004). Furthermore, conducting a nearest neighbourhood analysis is simpler and less ambiguous when using a hexagonal grid. Hexagons also have a shorter perimeter than a square of equal area, which potentially reduces bias due to edge effects (Krebs 1989). A square with unit area has a perimeter of length 4 , whereas the perimeter of a hexagon with unit area is 3.722 , so the edge-to-area ratio of a hexagon matches that of a square with $15.5 \%$ more area. Also, some parts of a square are farther from its centre than any part of a hexagon of equal area, so the average distance from the centre of a square with unit area is 0.3826 , whereas the average distance from the centre of a hexagon with the same area is 0.3772 (Birch, Oom, and Beecham 2007).

With a large quantity of data collected-some emotional mapping activities had over 2,000 respondents and gathered over 40,000 features-it was necessary to code new functionality in order to filter the data based on the respondents' gender, age, education, etc. A further improvement was the ability to compare data across time through simple swipe visualisation inspired by the Esri StoryMap platform. This is often used when, after a year's break, a municipality runs a workshop with the same questions. The swipe allows the public to compare the results easily without the need for any programming or GIS skills. At the time of this writing, the current version of the app allows for the collection and visualisation of vector data (points, lines, and polygons), and furthermore it is possible to add complex questions to the map and to assign values to collected features. The visualisation consists of heat map options, a filtering option, simple features with an optional swipe function, and hexagons.

\section{REAL LIFE DEPLOYMENT}

Since 2OI4, THIRTY-FIVE MEMber municipalities of the HCCZ network have conducted forty-six emotional mapping workshops. They all implemented the analogue map workshop and most of them $(n=29)$ used the digital version in order to broaden data collection and engage various types of respondents. Each city had its own range of questions, usually between five and seven in number, and these reflected the planning ideas and what was needed in 
the city. The questions ranged from the generic, "Where do you like it?" and "Where is it ugly?", to the quite specific, "Where do you have problems with parking?" and, "Where should the city place the new Edison statue?". The most common questions were related to the perception of safety, both during the day and at night, regarding walking, cycling, and driving. There were also positive questions: the most common ones were about pleasant places, about how people spent their free time, and their pride in the city (important landmarks, etc.). As the answers and quantitative involvement of the citizens vary, the results are used differently.

The most common use of the results is in the confirmation of what is already known, because civil servants often lack time as well as support from the government to draw any long-term conclusions from the mapping. Nevertheless, some municipalities used the results of the mapping workshops as a preliminary study and employed the data in
SWOT analysis, strategic planning analysis, and other applications. If the workshop subject was more specific, such as safety mapping (Pánek, Pászto, and Marek 2017; Pánek, Pászto, and Šimáček 2018), neighbourhood revitalisation (Pánek and Pászto 2017), air pollution (Pánek et al. 2017), or bicycle infrastructure (Pánek and Benediktsson 2017), the results were often used for white papers, policy papers, or urban studies.

Often the emotional mapping workshops are connected with public events such as Earth Day or neighbourhood festivals. In such cases, non-profit organisations usually create emotional maps of smaller areas (neighbourhoods, squares) in order to draw public attention to planning issues and the use of public spaces. These attempts strongly depend on collaboration with the municipality, as there is sometimes a lack of willingness to participate as a result of past experiences where expectations were not fulfilled (Botes and van Rensburg 2000).

\section{RESULTS}

This PAPER IS INTENDED to show how I developed an emotional mapping methodology and participatory mapping platform, while reflecting on my failures in order to help others not make such mistakes. So in this results section, I will present only one case study. The case study was implemented in the Prague 12 district (approx. 55,000 inhabitants) from September 2016 to November 2017 and it consisted of three mapping activities: a workshop at a community meeting (Figure 8) with an online emotional mapping extension, the creation of maps for use by the local police force (LPF), and a specialised school-surroundings safety mapping.

On the $22^{\text {nd }}$ of September 2016, 92 citizens participated in a Forum of the Healthy City meeting held in Prague 12, and this was where the paper-based emotional map of the district was created. This was followed by the participation of 233 respondents who completed the online emotional map between September and December 2016. The results from two collections included 2,696 points from six spatial questions. The questions were:

- Where is it dangerous? (point + comment)

- Where is it interesting? (point + comment)

- Where do you relax? (point + comment)
- Where do you miss something? (point + comment)

- Where is there an obstruction? (point + comment)

- Where do you meet with friends? (point + comment)

The results were presented in an emotional mapping report with maps and web visualisations, and the Prague $12 \mathrm{mu}-$ nicipality requested a specialised map based on answers to the "Where is it dangerous?" question for internal use by

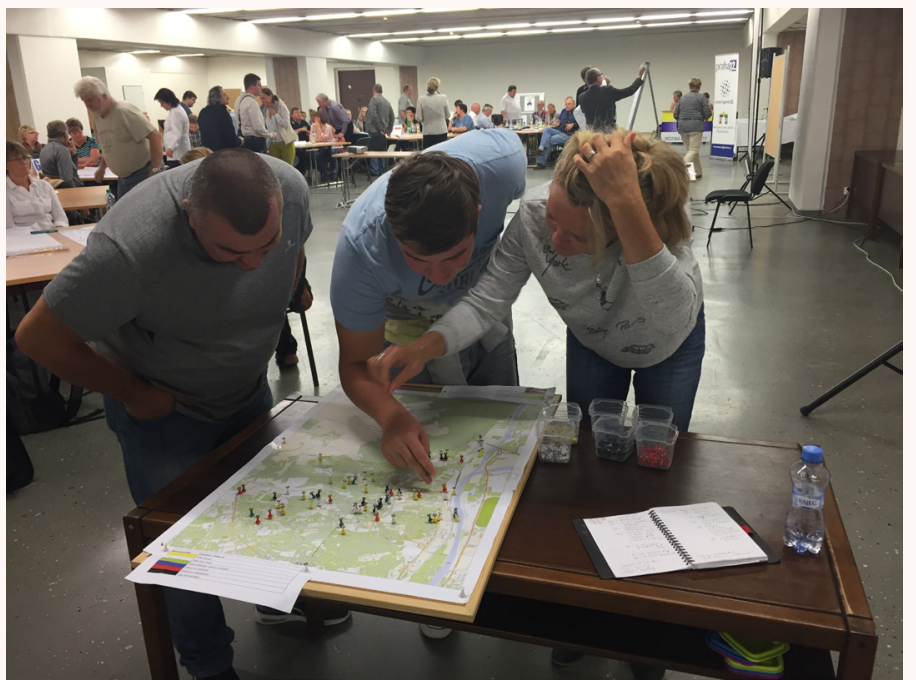

Figure 8. Emotional mapping workshop at the community meeting in the Prague 12 municipality. 
the local police. Based on the respondents' comments, the police representative divided points from this question into six categories (homeless; alcohol and drugs; traffic that can be solved by LPF; traffic that cannot be solved by LPF; other; not specified), and each police patrol received a map with designated places they were instructed to visit at least twice a month in order to monitor the issues reported by the citizens.

Based on the experience of using the emotional mapping workshop to improve the perception of safety in the district, the municipality decided to organize a large-

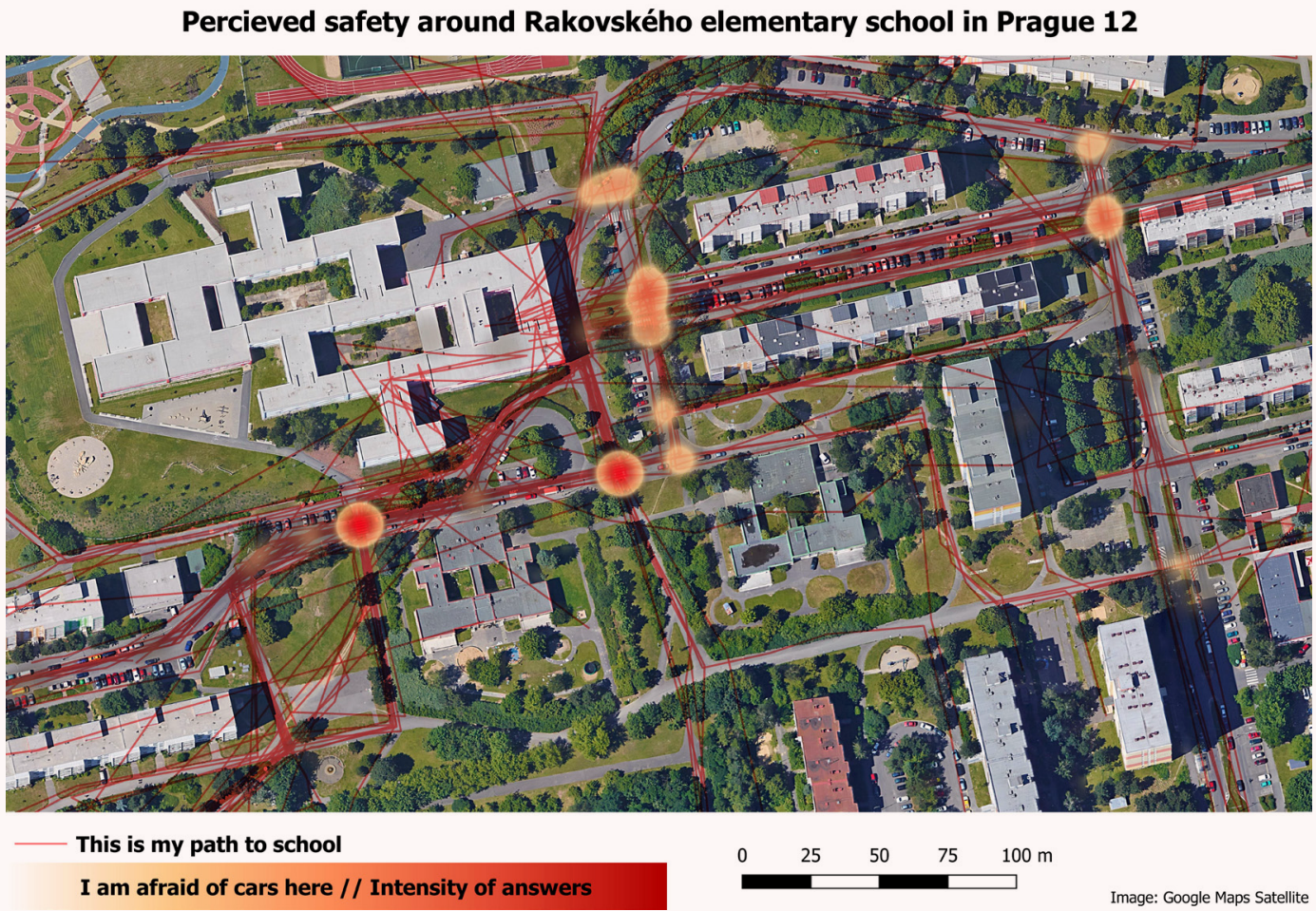

Figure 9. Example of a perception of safety map given to the school principals. scale safety mapping exercise among the grammar school pupils in the district. An online map was created with five spatial questions related to the perception of safety around local grammar schools. The questions, prepared in cooperation with teachers, police, and the district representatives were:

- This is my path to school (line)

- I am afraid of cars here (point + comment)

- It is uncomfortable here (point + comment)

- I like it here (point + comment)

- I spend my free time here (point + comment)

Besides the spatial information and comments, information was also collected about school, gender, grade, and how pupils annotated the map (alone, at school, with

parents). Each school had its own access code, so only pupils from that specific school could annotate the map. Once the code was entered, the map centred and zoomed in on the school surroundings and pupils could start entering their answers. A total of 990 pupils from eight schools took part in the mapping activity. While the gender balance of the pupils was quite even, age was unevenly distributed. The map was mainly completed by pupils between the $4^{\text {th }}$ and $9^{\text {th }}$ grades, and this was generally because the younger pupils do not walk as independently and freely around their schools as the older ones and they are more often driven to school by parents, while the older $\mathrm{pu}^{-}$ pils usually use public transport or walk alone. The majority (81\%) of the maps were made at schools and the final results, including maps (Figure 9), reports, and statistics, were delivered to city representatives as well as school principals and local police forces.

\section{DISCUSSION AND CONCLUSIONS}

Although it CAn Be Argued that the emotional mapping workshops are only an extension of the inequitable and preferential participation for those with skills, knowledge, and opportunities, it also has to be noted that in 29

electronic emotional maps, 6,343 people expressed ideas about their community, and furthermore several hundred citizens took part in the emotional mapping workshops at community meetings in their cities. The utilisation of 
online methods for community participation definitely carries the burden of the digital divide, where some people have easier and more comfortable access to the internet while others, especially the elderly, still lack opportunities to participate. Nevertheless, I see an opportunity in combining both offline and online data collection methods in order to open the participation process to as many citizens as possible.

Cities are complex systems with several social, cultural, and spatial processes, so it is difficult to use only one participatory mapping approach to address all the issues and contact the necessary target groups. Across the discipline, participatory mapping platforms struggle to achieve a critical mass of respondents in order to justify their deployment and the representativeness of the results. The emotional mapping workshop methodology presented in this paper, based on a combination of paper maps at local meetings and a modern web-mapping application, can further contribute to our understanding of how public participation and PPGIS can help build stronger and more resilient communities, while climbing the ladder of participation (Arnstein 1969).
The engaged municipalities agreed that participatory mapping workshops such as the one presented in this paper have value and the results often bring interesting insights. Nevertheless, the main contribution of emotional mapping workshops was seen in the creation of the notion of engagement. Over the past three years various methods for the collection and visualisation of urban perceptions have been tested. I am aware that there is still room for further development and improvement, and that it is also necessary to share the continuous challenges and failures. But, based on experience gained from the emotional mapping workshops, I can confidently say that emotional maps, as a tool for the participatory crowdsourcing of citizens' perceptions of their urban environment, have the potential to attract citizens' attention and to deliver tangible results that are readable and acceptable to municipality representatives. Further testing and comparison with similar platforms that already exist (Maptionnaire, GeoLive, GeoCitizen, etc.) is still needed. Therefore, this paper is also an open invitation for further collaboration in the area of emotional mapping, and it is also a contribution to discussions concerning the terminology and definitions of emotional mapping.

\section{ACKNOWLEDGEMENT}

This work was supported by the Czech Science Foundation within a project titled "Democratic Innovations at the Local Level - Case study of the Czech Republic, Poland and Slovakia" (No. 17-20569S) and by the project "Spatial Exploration of Economic Data: Methods of Interdisciplinary Analytics (Spationomy)," funded by the European Union within the Erasmus+ programme (No. 2016-1-CZ01-KA203-024040).

\section{REFERENCES}

Arnstein, Sherry. 1969. "A Ladder of Citizen

Participation." Journal of the American

Planning Association 35 (4): 216-224. doi:

$10.1080 / 01944366908977225$.

Art \& Cartography Commission of the International Cartographic Association. 2014. "Mapping Ephemeralities | Art \& Cartography on WordPress. com." Accessed April 27, 2018. https://artcarto. wordpress.com/2014/11/10/mapping-ephemeralities.
Bergner, Benjamin S., Peter Zeile, Georgios

Papastefanou, Werner Rech, and Bernd Streich. 2011. "Emotional Barrier-GIS - A New Approach to Integrate Barrier-Free Planning in Urban Planning Processes." In Proceedings of REAL CORP 2011, edited by Manfred Schrenk, Vasily V. Popovich, Peter Zeile, and Pietro Elisei, 247-257. Schwechat, Austria: Competence Center of Urban and Regional Planning. http://realcorp.at/archive/CORP2011_27.pdf. 
Birch, Colin, Sander Oom, and Jonathan Beecham. 2007. "Rectangular and Hexagonal Grids Used for Observation, Experiment and Simulation in Ecology." Ecological Modelling 206 (3-4): 347-359. doi: 10.1016/j. ecolmodel.2007.03.041.

Boschmann, E. Eric, and Emily Cubbon. 2014. "Sketch Maps and Qualitative GIS: Using Cartographies of Individual Spatial Narratives in Geographic Research." The Professional Geographer 66 (2): 236-248. doi: 10.1080/00330124.2013.781490.

Botes, Lucius, and Dingle van Rensburg. 2000. "Community Participation in Development: Nine Plagues and Twelve Commandments." Community Development Journal 35 (1): 41-58. doi: 10.1093/ $\mathrm{cdj} / 35.1 .41$.

Brown, Gregory, and Marketta Kyttä. 2014. "Key Issues and Research Priorities for Public Participation GIS (PPGIS): A Synthesis Based on Empirical Research.” Applied Geography 46: 122-136. doi: 10.1016/j. apgeog.2013.11.004.

Brown, Gregory, and David V. Pullar. 2012. "An Evaluation of the Use of Points versus Polygons in Public Participation Geographic Information Systems Using Quasi-Experimental Design and Monte Carlo Simulation." International Journal of Geographical Information Science 26 (2): 231-246. doi: 10.1080/13658816.2011.585139.

Burian, Jaroslav, Vít Pászto, and Barbora Langrová. 2014. "Possibilities of the Definition of City Boundaries in GIS - the Case Study of a Medium-Sized City." In 14th SGEM GeoConference on Informatics, Geoinformatics and Remote Sensing, 3: 777-784. doi: 10.5593/SGEM2014/B23/S11.099.

Caragea, Cornelia A., Anna B. Squicciarini, Sam B. Stehle, Kishore A. Neppalli, and Andrea B. Tapia. 2014. "Mapping Moods: Geo-Mapped Sentiment Analysis during Hurricane Sandy.” In ISCRAM 2014 Conference Proceedings - 11th International Conference on Information Systems for Crisis Response and Management, 642-51.
Chambers, Robert. 1994a. "Participatory Rural Appraisal (PRA): Challenges, Potentials and Paradigm." World Development 22 (10): 1437-1454. doi: 10.1016/0305-750x(94)90030-2.

1994b. "The Origins and Practice of Participatory Rural Appraisal." World Development 22 (7): 953-969. doi: 10.1016/0305-750x(94)90141-4.

_. 1994c. "Participatory Rural Appraisal (PRA): Analysis of Experience.” World Development 22 (9): 1253-1268. doi: 10.1016/0305-750X(94)90003-5.

2003. Whose Reality Counts? Putting the First Last. London: ITDG Publishing. doi: 10.3362/9781780440453.

Curtis, Jacqueline W. 2012. "Integrating Sketch Maps with GIS to Explore Fear of Crime in the Urban Environment: A Review of the Past and Prospects for the Future." Cartography and Geographic Information Science 39 (4): 175-186. doi: 10.1559/15230406394175.

D’Antona, Álvaro De Oliveira, Anthony D. Cak, and Leah K. VanWey. 2008. "Collecting Sketch Maps to Understand Property Land Use and Land Cover in Large Surveys." Field Methods 20 (1): 66-84. doi: 10.1177/1525822X07309354.

Demerath, Nicholas. 1947. "Ecology, Framework for City Planning.” Social Forces 26 (1): 62-67. doi: $10.2307 / 2572606$.

Doran, Bruce J., and Melissa B. Burgess. 2011. Putting Fear of Crime on the Map: Investigating Perceptions of Crime Using Geographic Information Systems. New York: Springer Science \& Business Media. doi: 10.1007/978-1-4419-5647-7.

Economic Opportunity Act of 1964. Pub. L. No. 88452, 78 Stat. 508. https://www.gpo.gov/fdsys/pkg/ STATUTE-78/pdf/STATUTE-78-Pg508.pdf.

Ekman, Paul. 1992. "An Argument for Basic Emotions." Cognition and Emotion 6 (3-4): 169-200. doi: 10.1080/02699939208411068. 
Ennis, Daniel M., and John M. Ennis. 2013. "Mapping Hedonic Data: A Process Perspective." Journal of Sensory Studies 28 (4): 324-334. doi: 10.1111/ joss.12048.

Gould, Peter, and Rodney White. 1974. Mental Maps. Harmondsworth, UK: Pelican Books. doi: 10.4324/9780203163757.

Griffin, Amy L., and Julia McQuoid. 2012. "At the Intersection of Maps and Emotion: The Challenge of Spatially Representing Experience.” Kartographische Nachtrichten 62 (6): 291-299.

Guldi, Jo. 2017. "A History of the Participatory Map.” Public Culture 29 (1): 79-112. doi: 10.1215/08992363-3644409.

Huck, John, Duncan Whyatt, and Paul Coulton. 2014. "Spraycan: A PPGIS for Capturing Imprecise Notions of Place." Applied Geography 55: 229-237. doi: 10.1016/j.apgeog.2014.09.007.

Jankowski, Piotr, Michał Czepkiewicz, Marek Młodkowski, and Zbigniew Zwoliński. 2016. "GeoQuestionnaire: A Method and Tool for Public Preference Elicitation in Land Use Planning." Transactions in GIS 20 (6): 903-924. doi: 10.1111/ tgis.12191.

Jiang, Bin, and Lars Harrie. 2004. "Selection of Streets from a Network Using Self-Organizing Maps." Transactions in GIS 8 (3): 335-350. doi: 10.1111/j.1467-9671.2004.00186.x.

Kitchin, Robert M., Mark Blades, and Reginald G. Golledge. 1997. "Understanding Spatial Concepts at the Geographic Scale without the Use of Vision." Progress in Human Geography 21 (2): 225-242. doi: 10.1191/030913297668904166.

Kocich, David. 2018. "Multilingual Sentiment Mapping Using Twitter, Open Source Tools, and Dictionary Based Machine Translation Approach.” In Dynamics in GIscience, edited by Igor Ivan, Jiří Horák, and Tomáš Inspektor, 223-238. Ostrava, Czech Republic: Springer, Cham. doi: 10.1007/978-3-319-61297-3_16.
Korpela, Kalevi. 2002. “Children's Environment.” In Handbook of Environmental Psychology, edited by Robert B. Bechtel and Arza Churchman, 363-373. New York: Wiley.

Krebs, Charles J. 1989. Ecological Methodology. New York: Harper Collins.

Lynch, Kevin. 1960. The Image of the City, Volume 1. Cambridge: MIT Press.

Mody, Ruturaj N., Katharine S. Willis, and Roland Kerstein. 2009. "WiMo: Location-Based Emotion Tagging." In Proceedings of the 8th International Conference on Mobile and Ubiquitous Multimedia. Cambridge: ACM. doi: 10.1145/1658550.1658564.

Nold, Christian. 2009. Emotional Cartography: Technologies of the Self. http://emotionalcartography. net/EmotionalCartography.pdf.

Pánek, Jiří. 2016. "From Mental Maps to GeoParticipation.” The Cartographic Journal 53 (4): 300-307. doi: 10.1080/00087041.2016.1243862.

Pánek, Jiř́i, and Karl Benediktsson. 2017. "Emotional Mapping and Its Participatory Potential: Opinions about Cycling Conditions in Reykjavík, Iceland.” Cities 61 (1): 65-73. doi: 10.1016/j.cities.2016.11.005.

Pánek, Jiří, Lenka Mařincová, Lenka Putalová, Jiří Hájek, and Lukáš Marek. 2017. "Crowdsourcing of Environmental Health Quality Perceptions: A Pilot Study of Kroměříž, Czech Republic.” In Citizen Empowered Mapping, edited by Michael Leitner and Jamal Jokar Arsanjani, 261-280. Cham, Switzerland: Springer. doi: 10.1007/978-3-319-51629-5.

Pánek, Jiří, and Vít Pászto. 2017. "Emotional Mapping in Local Neighbourhood Planning: Case Study of Př́bram, Czech Republic.” International Journal of E-Planning Research 6 (1): 1-22. doi: 10.4018/ IJEPR.2017010101. 
Pánek, Jiř́i, Vít Pászto, and Lukáš Marek. 2017.

"Mapping Emotions: Spatial Distribution of Safety

Perception in the City of Olomouc." In Lecture Notes in Geoinformation and Cartography: The Rise of Big Spatial Data, edited by Igor Ivan, Alex Singleton, Jiří Horák, and Tomáš Inspektor, 211-224. Cham, Switzerland: Springer International Publishing. doi: 10.1007/978-3-319-45123-7.

Pánek, Jiří, Vít Pászto, and Petr Šimáček. 2018. “Spatial and Temporal Comparison of Safety Perception in Urban Spaces. Case Study of Olomouc, Opava and Jihlava." In Dynamics in GIScience, edited by Igor Ivan, Jiří Horák, and Tomáš Inspektor, 333-346. Cham: Springer International Publishing. doi: 10.1007/978-3-319-61297-3_24.

Perkins, Christopher. 2009. "Performative and Embodied Mapping." In International Encyclopedia of Human Geography, edited by Rob Kitchin and Nigel Thrift, 126-132. Oxford: Elsevier.

Raslan, Rania, Khaled Al-Hagla, and Ali Bakr. 2014. "Integration of Emotional Behavioural Layer 'EmoBeL' in City Planning." In Proceedings of REAL CORP 2014, edited by Manfred Schrenk, Vasily V. Popovich, Peter Zeile, and Pietro Elisei, 309-317. Schwechat, Austria: Competence Center of Urban and Regional Planning.
Rød, Jan Ketil, Ferjan Ormeling, and Corné van Elzakker. 2001. "An Agenda for Democratising Cartographic Visualisation.” Norsk Geografisk Tidsskrift 55 (1): 38-41. doi: 10.1080/00291950120034.

Spencer, Christopher, and Jill Dixon. 1983. "Mapping the Development of Feelings about the City: A Longitudinal Study of New Residents' Affective Maps." Transactions of the Institute of British Geographers 8 (3): 373-383. doi: 10.2307/622051.

Šerý, Miloslav, and Petr Šimáček. 2012. "Perception of the Historical Border between Moravia and Silesia by Residents of the Jeseník Area as a Partial Aspect of Their Regional Identity (Czech Republic)." Moravian Geographical Report 20 (2): 36-46.

Taylor, Nigel. 1998. Urban Planning Theory Since 1945. London: SAGE. doi: 10.4135/9781446218648.

Tulloch, David L. 2007. "Many, Many Maps: Empowerment and Online Participatory Mapping." First Monday 12 (2). doi: 10.5210/fm.v12i2.1620.

Vlok, Chris, and Jiř́i Pánek. 2012. "CAMP for Change in the Bojanala Region of North West Province." In GISSA Ukubuzana 2012 Conference Proceedings. Johannesburg: EE Publishers.

Zadra, Jonathan R., and Gerald L. Clore. 2011. "Emotion and Perception: The Role of Affective Information." Wiley Interdisciplinary Reviews: Cognitive Science 2 (6): 676-685. doi: 10.1002/wcs.147. 